\title{
Purification and Partial Characterization of an Actin-Like Protein from Cricket Early Egg Plasmodium
}

\author{
J. G. Moser \\ Biologisehes Institut I (Zoologie), Universität Freiburg (Germany)
}

Received March 19, 1973

Summary. The purification of an actin-like protein from cricket egg yolk plasmodia ${ }^{1}$ by different selective extraction procedures, ammonium sulphate precipitation, ion exchange and immunoabsorption chromatography is described. Criteria of purity from analytical ultracentrifugation, SDS-disc electrophoresis, and immunoelectrophoresis are presented. Immunodiffusion analysis was used to control the success of the purification procedures.

The molecular weight of the monomeric form is $60000 \pm 10 \%$. Polymerization to pearlchain aggregate structures occurs under different conditions in $0.1 \mathrm{M} \mathrm{KCl}$ in the presence of ATP. Vinblastine precipitation leads to similar structures. Possibly related structures and the possible rôle of this protein in organizing movements in the plasmodial system are discussed.

\section{Introduction}

Evidence is accumulating that the functional "luxury" protein system of actomyosin is not restricted to muscle cells. Ishikawa et al. (1969) demonstrated actin in manifold mammalian cell types other than muscle by its binding capacity to heavy meromyosin. This method was extended to homogenates of the early chick embryo by Hitchcock (1971) to differentiate between the several filament types observed under the electron microscope. Proteins of the actin type were isolated from myxomycete plasmodia (Hatano and Oosawa, 1968), from amoebae (Weihing and Korn, 1969), and structurally characterized (for review see Hatano, 1972). Supplementary to the actin component these organisms were shown to contain an equivalent to myosin (Ts'o et al., 1956; Adelman and Taylor, 1969; Pollard, 1971; Hatano, 1971). A tropomyosin-like protein was found by Tanaka. and Hatano (1972) in Physarum. These findings support the working hypothesis that at least amoeboidally moving organisms contain the complete set of actomyosin components.

Studying the influence of cytochalasin B on different morphogenetic processes, Wessels et al. (1971) were able to elucidate the abundance and significance of microfilamental contractile systems in many developmental events. The filaments concerned are 40-50 $\AA$ thick as shown by electron microscopy. This is about half the width of muscular actin filaments. Actin-like proteins were further prepared

1 In early phases of insect development the egg nuclei divide without forming cellular barriers. Up to the moment of primary and secondary cell membrane formation these giant multinucleated cells are defined here-by analogy - as "plasmodia". In the cricket egg the onset of cell formation is yet a matter of controversy due to inherent difficulties of egg fixation for the purposes of electron microscopy. 
from sea urchin eggs (Miki-Noumura and Oosawa, 1969), and from thrombocytes (Bettex-Galland and Luscher, 1959; Shepro et al., 1969).

Actin-like proteins undergo G-F-transformation forming unidirectional double-superhelical filaments from 41000-60000 Dalton subunits. The filaments complex with heavy meromyosin (Huxley, 1963; Pollard et al., 1970; Nachmias and Huxley, 1970; Miki-Noumura and Oosawa, 1969). Heterologous actomyosins from rabbit myosin and an actin-like protein from the sources mentioned above show superprecipitation in the presence of ATP and the typical $\mathrm{Mg} \cdots-\mathrm{Ca} \cdots$ activated actomyosin ATPase activity at $0.1 \mathrm{M}$ ionic strength (Hatano and Tazawa, 1968; Miki-Noumura and Oosawa, 1969; Weihing and Korn, 1969). Further similarities to muscular actin were derived from the amino acid composition.

Previously to these more recent findings Krause and Sander (1962) postulated a strictly localized filamentous system governing the early organizing movements during germ band formation from blastoderm material in insect eggs. This hypothesis was supported first by electron microscopic observations of filamentous structures in insect egg yolk plasmodia (Körner, 1969; Wolf, 1969). The spatially programmed moving mechanism was shown to be of considerable stability against longlasting anoxia (Hunn, 1968) and external mechanical manipulation (Vollmar, 1972). In favour of the filament hypothesis we reported previously that antisera prepared against cricket adult natural actomyosin react with homogenates of the corresponding eggs. At least four different antigens were revealed by these antisera in eggs during the preblastoderm stage (Moser et al., 1970). These antigens do not appear to be identical to any of the adult actomyosin components which were shown to develop later during embryonic cell differentiation (Bode and Moser, 1971).

One of these antigens seems to be of the actin type. The following sections refer to an immunological characterization of this protein, to its purification, and to a preliminary characterization of its subunit.

\section{Material and Methods}

Crickets (Acheta domesticus, Gryllus bimaculatus) were reared in stock cultures in this laboratory or purchased from Grigfarm, Wittinsburg, Switzerland. Eggs were collected daily and kept in Petri dishes under tap water for further development. Different developmental stages were selected under the microscope. The eggs were frozen at $-20^{\circ} \mathrm{C}$ or used immediately for further processing.

Antisera were obtained and immunological tests were performed as described previously (Moser et al., 1970; Moser et al., 1972). Details are given in the legends to figures.

Rabbit myosin was prepared according to Weber (1956). Some supplementary experiments were performed according to A. G. Szent-Györgyi (1951) followed by the ultracentrifugal treatment according to Weber (1956).

Crude immunoglobulin $\mathrm{G}$ (IgG) was obtained from pooled hyperimmune mouse ascitic fluid by ammonium sulphate fractionation between 30 and $50 \%$ saturation. The precipitate was dialyzed against $0.5 \mathrm{M} \mathrm{KCl}-50 \mathrm{mM} \mathrm{NaHCO}_{3}$ at $\mathrm{pH} 8.5$, diluted to $3 \mathrm{mg}$ protein $/ \mathrm{ml}$, and coupled to cyanbromide-activated Sepharose 4 B (Pharmacia, Uppsala, Sweden) according to the suggestions given by the supplier (derived from Morrison and Koshland, 1972).

Gel electrophoresis was performed in $6 \mathrm{~mm}$ diameter glass tubes containing $2 \mathrm{ml}$ of $7.5 \%$ acrylamide-SDS-gel (Shapiro et al., 1967) at $7.5 \mathrm{~mA} /$ tube constant current for $90 \mathrm{~min}$. For molecular weight determinations, aldolase, bovine serum albumin, ovalbumin, and chymo- 
trypsinogen were used as inner standards. Protein was determined by the method of Lowry et al. (1951).

For electron microscopy negative staining of the preparations was done on carbon-coated formvar copper grids with $1 \%$ phosphotungstic acid (neutralized to $\mathrm{pH} 7.0$ ) or with $1 \%$ aqueous uranyl acetate. Routinely a Zeiss EM9 A electron microscope was used for observations at $40000 \times$ magnification. Higher resolution was obtained with a Siemens Elmiskop I electron microscope operated at $80 \mathrm{kV}$ and $16 \mu \mathrm{A}$ and at $60000-80000 \times$ magnification.

\section{Results}

\section{A. Immunological Reactions between Egg Proteins and} Antisera Against Adult Muscular Actomyosin Preparations

To control the efficiency of the purification procedures described below, two types of antisera were prepared: antisera against whole egg homogenates of the cricket species in question (Nünemann and Moser, 1969), and antisera against different highly purified muscle actomyosin preparations from adults (Moser et al., 1970; Bode and Moser, 1971; Moser et al., 1972). Two possible sources of error have to be overcome when preparing the latter type of antisera: antisera directed against crude actomyosin preparations may react (1) with egg yolk proteins if female sex-specific blood or fat body antigens are not strictly excluded during purification of the immunogen; for the same reasons (2) reactions against mitochondrial, ribosomal, nuclear, and reticular components common to structural material of all cell types have to be avoided. 15 of the 73 charges of anti-actomyosin. antisera used during this study were prepared by immunization of NMRI-HAN mice with pure male actomyosin. These antisera gave essentially the same results as obtained with antisera against bulk preparations from muscle of both sexes. So the cross reactions reported here are unlikely to depend on female sex-specific protein impurities. Furthermore, the antisera were critically examined for reactivity against muscle mitochondrial, microsomal, and nuclear fractions including plasma membrane fragments, collagen, and glycogen. One charge showing reactivity with the microsomal fraction was excluded from further experiments. In all other antisera reactivity was found to be correlated with structural elements of the contractile system.

To enhance the polyvalent titres against minor and/or less immunogenic components of the actomyosin used in the immunization procedure, male actomyosin of Gryllus bimaculatus was modified in different ways. Best titres were obtained (1) by coupling the purified actomyosin to diazotized sulphanilic acid or (2) by using the insoluble fraction containing light meromyosin (LMM) and actin obtained during preparation of heavy meromyosin (HMLI) from actomyosin by tryptic digestion (cf. Ikemoto et al., 1968, for method). Fig. 1 b, c demonstrates the striking difference in reactivity between tests with antisera directed against unmodified actomyosin (b) and more recent experiments with antisera directed against the trypsin-digested actomyosin fraction mentioned above (c). Both precipitin line patterns show clearly a reactivity of the egg plasmodial proteins with antisera directed against actomyosin.

A more detailed evaluation of the precipitin patterns obtained with 22 antisera prepared with the LMM-actin-fraction as the immunogen is presented in Table 1. Details of 15 of the most significant patterns are redrawn according to the photo- 


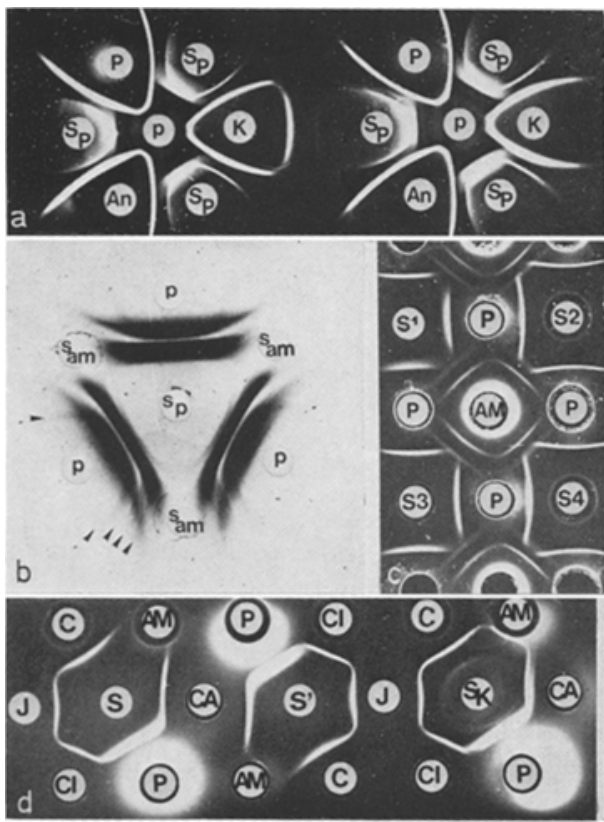

Fig. $1 \mathrm{a}-\mathrm{d}$

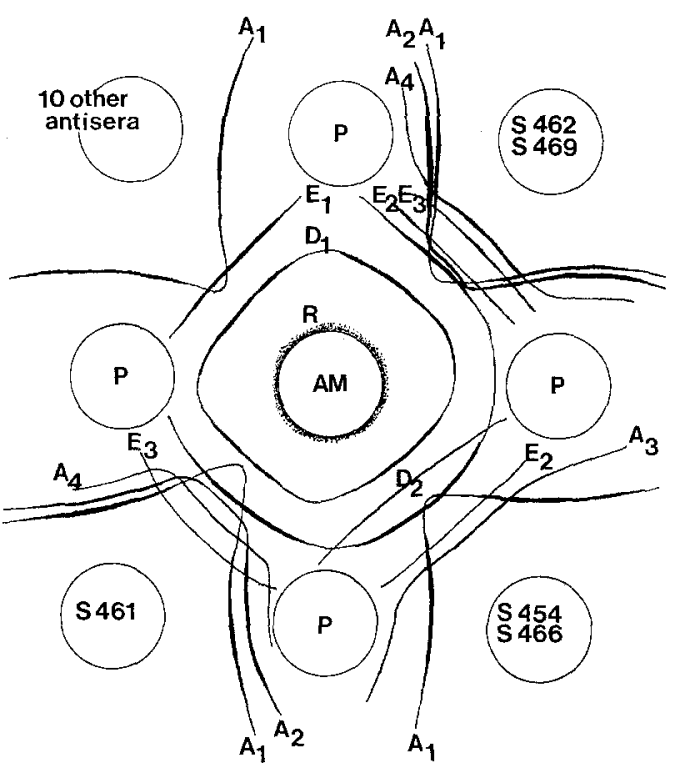

Fig. 2

Fig. 1 a-d. Species-specificity of yolk plasmodial proteins in $G$. bimaculatus and $A$. domesticus. Detection of A-antigens by immunological reactions. a Two different antisera $S_{p}$ directed against $G$. bimaculatus total egg proteins (stage: preblastoderm formation) are reacted with $A$. domesticus egg extracts ( $p$ preblastoderm) and extracts from $G$. bimaculatus eggs in three different stages of development ( $P$ preblastoderm; $A n$ anatrepsis; $K$ katatrepsis). For comments see text. $b$ and $c$ Reaction of antisera directed against adult natural actomyosin of $A$ domesticus $\left(s_{a m}\right)$ and the LIMM-actin fraction of adult of natural actomyosin of $\theta$. bimaculatus (S1, S2, S3, S4) with total egg protein extracts of the corresponding species ( $p, P$ preblastoderm stage) e Shows a test arrangement similar to Fig. 2. The cross-reacting bands are (indicated by arrows in (b); rightangled precipitin lines around $P$ in (c) show the presence of components of the A-antigen group in the egg material. For evaluation cf. Fig. 2 and Tables 1 and 3. $\mathrm{d}$ A-antigens obtained during fractionation of egg protein extracts $(\mathrm{Cl}, \mathrm{C}, \mathrm{CA}, \mathrm{J}$; cf. Table 1) starting from egg homogenate ( $P$ preblastoderm stage) show identical components if reacted with three different antisera $\left(S, S^{\prime}, S_{K}\right)$. Two antisera $\left(S^{\prime}, S_{K}\right)$ reveal distinct identity with minor components of purified natural actomyosin $(A M)$

Fig. 2. Precipitin line patterns of 15 antisera reacted with adult male natural actomyosin and egg extracts ( $G$. bimaculatus; preblastoderm stage). Identity of the individual precipitin lines was confirmed by arranging antisera and several purified antigens according to Moser et al. (1972) and by comparison of the A-antigen specificities of three different typical antisera. Terminology and results of these and some further experiments are summarized in Table 1. The 10 antisera referred to on the left upper edge were combined in order to prepare $\gamma$-globulin with A1-specificity. This preparation was used in immunoabsorption chromatography experiments; cf. Fig. $4 \mathrm{~b}$

graphic evaluation of 72 test-plates and shown in fig. 2. Termini used to describe individual precipitin bands were given in previous communications of this laboratory (Bode and Moser, 1971; Moser et al., 1972). Using these antisera, in adult muscular actomyosin the following precipitin bands could be identified: $\mathrm{C}$ (not 
Table 1. Antigen patterns revealed by the Ouchterlony immunodiffusion test with 22 antisera prepared with the LMM-actin fraction from adult male actomyosin as the immunogen (* of. Fig. 2)

\begin{tabular}{|c|c|c|c|c|c|c|c|c|c|c|}
\hline \multirow{2}{*}{$\begin{array}{l}\text { Anti- } \\
\text { serum } \\
\text { No. }\end{array}$} & \multicolumn{10}{|c|}{ Antigens } \\
\hline & $\mathrm{A} 1$ & $\mathrm{~A} 2$ & A3 & $\mathrm{A} 4$ & D1 & D2 & E1 & $\mathrm{E} 2$ & E3 & $\mathrm{R}$ \\
\hline 451 & + & & & & + & & + & & & + \\
\hline 452 & + & & & & + & & & & & + \\
\hline 453 & + & & & & + & & & & & + \\
\hline $454^{*}$ & + & & + & & + & + & + & + & & + \\
\hline 455 & + & & & & + & & & & & + \\
\hline 456 & + & & & & + & & & & & + \\
\hline 457 & + & & & + & + & & + & & + & + \\
\hline 458 & + & & & & + & & + & & & + \\
\hline 459 & + & & & & + & & $(+)$ & & & + \\
\hline 460 & + & & & & + & & + & & & + \\
\hline $461^{*}$ & + & + & & + & + & & + & & + & + \\
\hline $462^{*}$ & + & + & & + & + & & + & + & + & + \\
\hline 463 & + & & & & + & & + & & & + \\
\hline 464 & + & & & & + & & + & & & + \\
\hline 465 & + & & & & + & & + & & & + \\
\hline $466^{*}$ & + & & + & & + & + & + & + & & + \\
\hline 467 & + & & & $(+)$ & + & $(+)$ & & & $(+)$ & + \\
\hline 468 & + & & & & + & & & & & + \\
\hline $469^{*}$ & + & + & & + & + & & + & + & + & + \\
\hline 470 & + & & & & + & & $(+)$ & & & + \\
\hline 471 & $(+)$ & & & & $(+)$ & & & & & + \\
\hline 472 & + & & & & $(+)$ & & $(+)$ & & & $(+)$ \\
\hline
\end{tabular}

Identities in adult muscle actomyosin (Moser et al., 1972): C3=tropomyosin B (not included); D1 = myosin; E1 $=\alpha$-actinin; $\mathbf{R}=$ actin.

included here; faintly revealed by 17 antisera $)=$ tropomyosin $\mathrm{B} ; \mathrm{D} 1=$ myosin; $\mathrm{E} 1=\alpha$-actinin; $\mathrm{R}$ (unspecific precipitate) = actin. $\mathrm{D} 2, \mathrm{E} 2$, and $\mathrm{E} 3$ have not yet been identified. $G$. bimaculatus egg antigen $A 1$ is precipitated as a sharp band by nearly all antisera. The minor components A2, A3, and A4 are revealed by 3, 2, and 5 individual antisera respectively. All these antigens seem to be present in highly purified natural actomyosin as evident from the more or less pronounced closing of the precipitin lines near the actomyosin containing test hole. Because of their very low concentration in natural actomyosin the purification of the respective antigens from actomyosin has not yet been established. As judged from the Ouchterlony tests, clearly visible precipitin bands of the A1-antigen were obtained with $0.2-2 \mu \mathrm{g}$ of the purified protein (see below).

Treatment of egg plasmodial extracts and skeletal muscle actomyosin with RNAse, DNAse, $\alpha$-amylase, and $\beta$-amylase did not affect the patterns. Pronase digestion and prolonged incubation with trypsin led to a time-dependent decrease of the band pattern giving evidence of the protein nature of the egg cross-reacting antigens in question. 
Some female larval and imaginal tissues known to be possible sources of egg yolk plasmodial proteins were investigated in a similar manner for reactions with antisera against skeletal actomyosin. These included larval and imaginal ovary, blood, fat body, mid intestine, and-for comparison-testes. Egg plasmodial protein and actomyosin samples were included in the test plates. Most pronounced reactions were obtained with mid intestine extracts. Medium reactions were seen with fat body and imaginal ovary, nearly none with blood, larval ovary, and testes. These reactions indicate the presence of structural proteins related to components of skeletal muscle actomyosin. To enhance their recovery from tissue homogenates rabbit skeletal myosin was added in excess to complex actin-like components during the preparation (Ishikawa et al., 1969; Hatano and Oosawa, 1968; Moser et al., 1972). The difference observed between larval and imaginal ovary indicates that the cross-reacting protein system is built up during the ultimate stage of oogenesis in terminal oocytes. Confirmative experiments to elaborate this statement are under investigation.

127 batches of antisera against egg yolk plasmodial components from either Gryllus bimaculatus or Acheta domesticus were checked during this study. A certain degree of cross-reactivity was observed between the egg proteins of the two species. Examples are given in fig. 1 (a). On the other hand the main cross-reacting antigen component if demonstrated by anti-actomyosin antisera in $G$. bimaculatus is not identical with the protein isolated under the same conditions from Acheta domesticus eggs despite its very similar structure as judged from electron micrographs (see below). Furthermore, only five batches of antisera against egg components, produced by two individual mice, showed a clearcut immunological identity between $G$. bimaculatus cross-reacting egg components and an individual fraction of actomyosin from skeletal muscle. These antisera may be used to elucidate the antigenic determinants leading to the commonly observed reaction of antisera against actomyosin with egg proteins (fig. $1 \mathrm{~d}$ ). The fraction carrying the respective determinants may be isolated from natural actomyosin by alkaline reducing treatment at low ionic strength. (ESF-fraction according to Hartshorne and Mueller, 1969), and be further purified by ammonium sulphate precipitation between 40 and $70 \%$ saturation. In the respective tests antigens from skeletal muscle showing reactivity with antisera prepared against egg proteins were included. The reaction of these antigen determinants with anti-actomyosin antisera is fully abolished by acetylation of the antigen with acetanhydride under alkaline conditions .

Despite the demonstrated nonidentity of the cross-reacting antigens of the two cricket egg species under investigation their common fates (intra-species cross-reactivity, solubility, structural similarity) led us to term them provisionally "A-antigen group"' (Moser et al., 1970; Bode and Moser, 1971). Depending on antiserum specificity up to four different antigens could be detected in homogenates of eggs in the preblastoderm stage and during the following periplasmic streaming phase. A fifth precipitin line could be visualized in egg preparations during germ band movement in anatrepsis. The earliest date to detect components of the Aantigen group is the time of terminal oocyte formation. The whole group persists to the time of hatching of the first larval instar. The A-group antigens differ in turnover behaviour from some transitory antigens of the late differentiating 

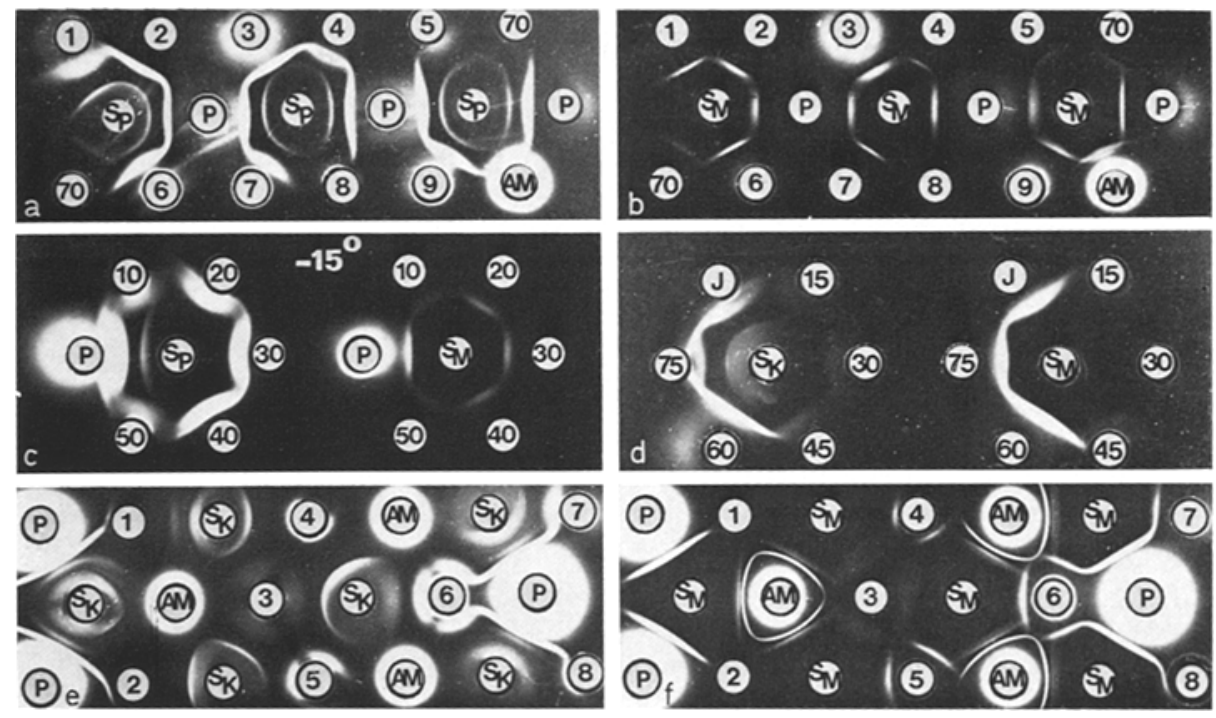

Fig. $3 a-f$. Immunological control of solubility fractionation of A-antigens from $G$. bimaculatus eggs (preblastoderm stage). Influence of added rabbit skeletal muscle myosin on purification of A1-antigen.

Common signs: Antisera $S$ directed against egg extracts from preblastoderm stage $\left(S_{P}\right)$, from katatrepsis stage $\left(S_{R}\right)$, and against adult male natural actomyosin $\left(S_{M}\right)$. Starting material: total protein from preblastoderm stage eggs $P$. $A M$ adult male natural actomyosin. The precipitin line patterns shown here are comparatively simple examples. Dependent on polyvalency of the antisera involved one may obtain patterns with a greater number of precipitin lines much more difficult to interpret for the reader at first glance. Each experiment was controlled with several polyvalent antisera of the $S_{P}, S_{K}$, and $S_{M}$ types.

a and $\mathbf{b}$ Purification of A-antigens without addition of rabbit myosin (route IV; cf. Table 2). Numerals 1-9 refer to the following steps: 1, 2 Supernatants from KCl-EDTA treatment of the egg homogenate. 3 Sediment obtained by precipitation of the $0.6 \mathrm{M}$ KCl-extract at $0.1 \mathrm{M} \mathrm{KCl} .4,5$ Supernatants of $\mathrm{NaHCO}_{3}$ treatment. 6 Extract with alkaline $\beta$-mercaptoethanol. $7,8,9$ Precipitates of extract 6 at 15, 40, and $70 \%$ sat. ammonium sulphate resp. Note heavy antigen losses at steps 1, 2, and 4 and the evident immunological identity of the A1-antigen to an antigen of the actomyosin system precipitated near the actin-containing ring-like precipitate around AM. $70=$ precipitate of the "desensitization supernatant" prepared by a similar route from natural actomyosin at $70 \%$ ammonium sulphate saturation. c Effect of glycerol treatment on the egg extract at 10, 20,30,40, and $50 \%$ glycerol concentration without addition of rabbit myosin $\left(-15^{\circ} \mathrm{C}\right)$. For comments see text. d Ammonium sulphate precipitation of the KJ-ATP extract from acetone-dried powder (ronte II; cf. Table 2) at $15,30,45,60,75 \%$ saturation. Note the crossing-over of the precipitin lines revealed by the antiserum $S_{K}$ : antigens $\mathrm{A} 3$ and $\mathrm{A} 4$ precipitate at $60 \%$ saturation meanwhile the $A 1$-antigen is obtained between 70 and $80 \%$ saturation. These differences depend on the precipitation time and are not always reproducibly noted with different preparations. e and $\mathbf{f}$ Purification of the A1-antigen with addition of rabbit myosin (route II; cf. Table 2). Numerals 1-8 refer to the following steps: 1 Glycerol extracts. $20.6 \mathrm{M} \mathrm{KCl-extract.} 3$ Supernatant after precipitation at $0.1 \mathrm{M} \mathrm{KCl}$. 4, 5 Supernatants from repeated $\mathrm{NaHCO}_{3}$-EDTA treatments. 6 Treatment with distilled water. 7,8 Sequential extraction of the acetone dried powder with $\mathrm{KJ}$-ATP at $0^{\circ} \mathrm{C}$ and $20^{\circ} \mathrm{C}$, respectively. Antigen losses occur during steps 4, 5, 6 (similar to the actin preparation according to Bárány et al., 1957) due to reduced interaction between myosin and the A1-antigen. 1, 2,3 (if compared to similar steps in Fig. 3a, b) show the stability of the complex. Recovery in the presence of myosin is significantly increased (see text). In AM, the following bands (read from position of antigen to position of antiserum) are visible: $\mathrm{R}, \mathrm{D}(1,2,3), \mathrm{E}(1,2)$ 
embryo (B-antigen group; Bode and Moser, 1971) as well as from major actomyosin antigens developed during embryonic muscle formation.

The purification and some immunological properties of the main component of the A-antigen group resembling an actin-like protein are described in the following section.

\section{B. Purification of the Actin-Like Protein from Cricket Egg Plasmodia}

The principal course of purification procedures employed in this study is given in table 2. The different ways in which a more or less specific purification of the main component of the A-antigen group was proved to result are indicated by roman numerals.

Table 2. Principal course of purification procedures employed to prepare the actin-like A-antigen

- 1st extraction

- 2nd extraction

- precipitation by dilution to

- washing of the sediment with

- drying of the residue with

route:

- 3rd extraction with

\section{$1 \mathrm{~g}$ egg material (+25 $\mathrm{mg}$ rabbit myosin)}

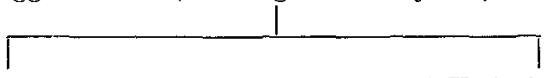

$10-15 \%$ buffered glycerol<smiles>C1CC1</smiles>

$0.6 \mathrm{M} \mathrm{KCl}(+5 \mathrm{mM}$ ATP, buffer $\mathrm{pH} 7)$

0.1. M KCl (+1 mM ATP, buffer pH 7)

$0.1 \mathrm{M} \mathrm{NaHCO}, 10 \mathrm{mM}$ EDTA

(icecold distilled water)

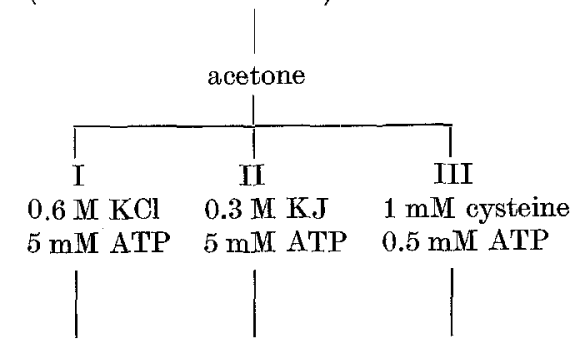

fractionation with ammonium sulphate

- dialysis and chromatography on

DEAE-cellulose

$0.1 \mathrm{M} \mathrm{KCl}-10 \mathrm{mM}$ EDTA

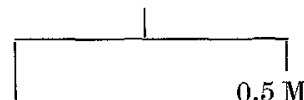

$0.5 \mathrm{M} \mathrm{KCl}-50 \mathrm{mM}$ borate $\mathrm{pH} 8.5$

$1 \mathrm{mM} \mathrm{NaHCO}$
IV

$1 \mathrm{mM}$ mercapto-

ethanol

$30 \mathrm{mM}$ EDTA

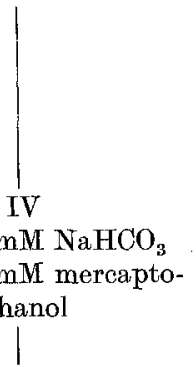

immunoabsorbent

- precipitation by

When processed with rabbit actomyosin the three routes indicated I, II, and III lead to crude preparations of muscular actin. Route IV refers to the immunological relation of the antigen in question to an antigen from cricket skeletal muscle. 
This antigen may be prepared from natural actomyosin by a treatment resembling the preparation of the EGTA-sensitizing fraction (ESF) of Hartshorne and Mueller (1969). The procedure involves a partial disintegration of the actin filament, and some monomeric G-actin is always found as a contaminant of the crude preparation. The contamination is readily separated by ammonium sulphate fractionation. Route $V$ uses the cross-reactivity with anti-actomyosin antisera to isolate the whole A-antigen group from relatively crude preparations of the egg plasmodial proteins.

As reported by several authors (e.g. Dejmal and Brookes, 1968) yolk proteins of orthopteran eggs are insoluble at $0.1 \mathrm{M} \mathrm{KCl} \mathrm{but} \mathrm{readily} \mathrm{soluble} \mathrm{at} 0.6$ to $1.0 \mathrm{M}$ $\mathrm{KCl}$. This behaviour interferes severely with the solubility of an actomyosin complex. So every preparation using conventional solubility fractionation must be heavily contaminated with unspecific yolk proteins. To separate bulk yolk proteins from the antigens in question a treatment with phosphate-buffered glycerol was found to be the most exhaustive method. The range between 10 and $50 \%$ was tested. The most adequate concentrations were 40 and $50 \%$ leaving most of the A-antigen components insoluble. The method was further improved by adding highly purified rabbit myosin to the egg homogenate in the presence of $0.5 \mathrm{mM}$ ATP at $60 \mathrm{mM}$ $\mathrm{KCl}$ concentration. Under these conditions almost none of the A-antigens was lost during further preparation steps. The homogenate was filtered through a glass pore filter to discard egg chorion particles and extracted for two 1 hour periods with $50 \%$ glycerol at $-5^{\circ}$ and $-15^{\circ} \mathrm{C}$. The rabbit myosin/A-antigen complex was collected by centrifugation at $20000 \times g$ for $30 \mathrm{~min}$ (Fig. $3 \mathrm{c}$ ).

As seen from electron micrographs of egg halves extracted under similar conditions the glycerol treatment leads to total dissolution of the yolk platelets and almost all periplasmic organelles. The remaining structure contains outer mitochondrial membranes, a network of thin periplasmic filaments, and some myelinated (phosphatide?) structures originating from yolk fat globules. So the protein components of the A-antigen group have to be eomponents of one or some of these structural elements.

Myosin binding of the A-antigens is being more extensively studied at present in this laboratory. Some observations reported here are of a preliminary character. The immunological tests indicate that minimally $15 \mathrm{mg}$ of purified rabbit myosin per gram egg fresh weight are necessary to bind the A-antigens completely. In isolation procedures we use routinely $20-25 \mathrm{mg}$ of myosin per gram fresh weight. The myosin complex is formed between $0.3 \mathrm{M}$ and $0.05 \mathrm{M} \mathrm{KCl} \mathrm{buffered} \mathrm{with} 25 \mathrm{mM}$ imidazole.HCl to $\mathrm{pH}$ 6.8. Complex formation leads to very stable aggregates hindering completely the diffusion of the A-antigens into the agar-gel used in immunodiffusion tests. The complex may be broken by removing divalent cations with alkaline EDTA and by further acetone treatment leading to myosin denaturation.

As indicated by the immunological tests this step is the most critical one during purification of the A-antigens. As shown in fig. $3(\mathrm{e}, \mathrm{f})$, all steps up to $\mathrm{NaHCO}_{3^{-}}$ EDTA treatment do not lead to antigen losses of more than traces. Before acetone treatment according to Bárány et al. (1957) EDTA has to be removed by a short extraction with distilled water. This extract if not centrifuged immediately 

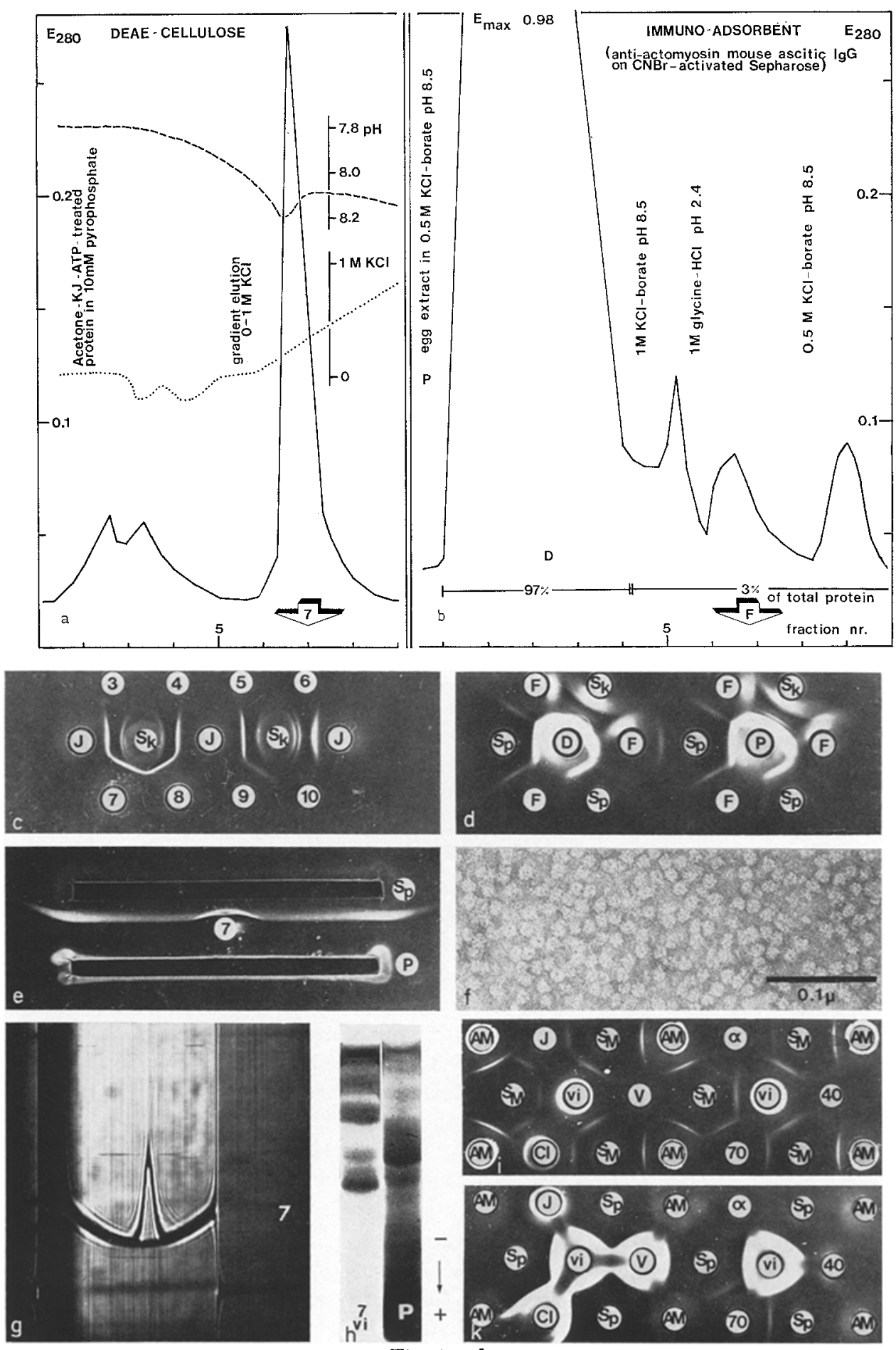

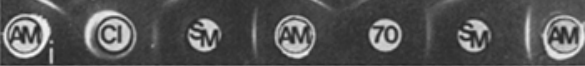

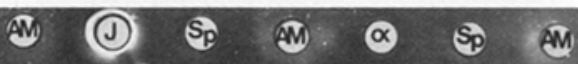

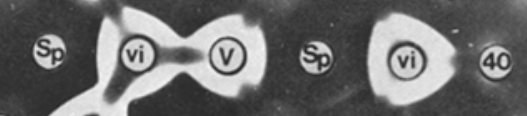

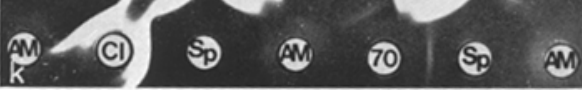

Fig. $4 \mathrm{a}-\mathrm{k}$ 
contains almost half of the A-antigens. So in some instances we abandoned this step without significant alteration to the further purification steps.

The following extraction of the acetone-dried powder is based on methods given by Straub (1942), Hatano and Oosawa (1968), and Miki-Noumura and Oosawa (1969). As judged from immunological tests best results were obtained with methods II and III at $0^{\circ} \mathrm{C}$. The latter preparations were unsuitable for spectrometric measurements since some iodide seems to be absorbed by the extracted protein, shifting absorption spectra to values interfering with measurements of ATPbinding. Addition of $\beta$-mercaptoethanol or dithiothreitol to all solutions employed could not prevent iodide absorption. As shown by immunological test (Figs. $1 \mathrm{~d}$, $3 \mathrm{e}, \mathrm{f})$ the protein components extracted from acetone-dried myosin/A-antigen complex are almost identical and can be further processed by identical methods.

Route IV employs bivalent cation removal at $0.1 \mathrm{M} \mathrm{KCl}$ leaving yolk proteins and the myosin/A-antigen complex in their insoluble state. After treatment with

Fig. 4a-k. Further purification of the actin-like A1-antigen by ion exchange and immunoabsorption chromatography. Further characterization of the antigen and its polymers. Sequence $(a, c, e, g, h)$ refers to chromatography on DEAE-cellulose, sequence $(b, d, f, i, k)$ to immunoabsorption chromatography on immobilized A1-specific globulin.

Symbols : $\alpha$ Purified $\alpha$-actinin from cricket adultnatural actomyosin. $A M$ Adult malenatural actomyosin. $C l, J$ Extracts from acetone-dried egg powder with $\mathrm{KCl}$ resp. KJ-ATP solutions (route I, II cf. Table 2). P $0.6 \mathrm{M} \mathrm{KCl-extract} \mathrm{from} \mathrm{eggs} \mathrm{(preblastoderm} \mathrm{stage).} V$ Glycerol extract from myosin-complexed egg homogenate (cf. Table 2). vi Vinblastine precipitates from chromatographically purified fractions. $S_{(p, k, M)}$ Antisera directed either against egg proteins $\left(S_{p, k}\right.$ : preblastoderm stage or katatrepsis stage as immunogens) or against natural actomyosin of the adult $\left(S_{M}\right)$. 40,70 Ammonium sulphate precipitates prepared from actomyosin "desensitation supernatant" (cf. Fig. $3 \mathrm{a}, \mathrm{b}$ and the text) at $40 \%$ and $70 \%$ saturation. a Chromatography of material obtained by route II (cf. Table 2) on DEAE-cellulose. Fraction 7 eluted at $0.3 \mathrm{M} \mathrm{KCl}$ during linear gradient elution was further analysed. ...... ionic strength of the eluate (as derived from continous recording of conductivity); ..... pH. b Immunoabsorption chromatography (route $V$, cf. Table 2) of egg extract (preblastoderm stage) on A1-specific immobilized globulin. For further characterization fractions 1-3 ( $D$ break-through peak) and fractions 5-9 ( $F$ eluted absorbed material) were combined. For characterization of antisera cf. Fig. 2, left upper edge, and Fig. 1c). c Immunodiffusion analysis of fractions 3-10 from DEAE-cellulose chromatography (cf. Fig. 3a). A1-antigen is recovered in fractions 7-9. d Immunodiffusion analysis of combined eluates $D, F$, and the starting material $(P)$ from immunoabsorption chromatography (cf. Fig. 3b). e Ossermann immunoelectrophoresis tests for homogeneity of the A1-antigen preparation isolated by ion exchange chromatography. Despite the inhomogenous distribution of polymers in SDS-gel electrophoresis (cf. Fig. $3 \mathrm{~h}$ ) this test points to homogeneity of the subunit. $\mathrm{f}$ The absorbed fraction $(F)$ of immunoabsorption chromatography was redialysed against $0.5 \mathrm{M} \mathrm{KCl}-50 \mathrm{mM}$ borate buffer $\mathrm{pH}$ 8.5. Negative staining with $1 \%$ aqueous uranyl acetate. Primary magnification $\times 80000$. Siemens Elmiskop I equipped with double condensor and anti-contamination device. g Analytical ultracentrifugation of fraction 7 (Fig. 3a) from ion exchange chromatography. Beckman Model E analytical ultracentrifuge. Phase angle 50 ; synthetic boundary cell; $44770 \mathrm{rpm} ; 28 \mathrm{~min}$ after reaching top speed. $1.2 \mathrm{mg}$ protein $/ \mathrm{ml}$ in $10 \mathrm{mM}$ pyrophosphatecitrate-1 mM $\beta$-mercaptoethanol $\mathrm{pH}$ 7.8. Note the irregular increase of diffraction due to polymers at the bottom of the cell. $\mathbf{h}$ SDS-disc electrophoresis of materials from ion exchange chromatography $(P, 7 v i)$. For comments see Fig. $3 \mathrm{e}$ and the text). $\mathbf{i}$ and $\mathbf{k}$ Characterization of vinblastine-precipitated material isolated by immunoabsorption chromatography (fraction $F$ ). Note the partial identity of the $\mathrm{A} 1$-antigen to a substance present in the adult muscle actomyosin fraction " 70 " 
$30 \mathrm{mM} \mathrm{NaHCO}$ the protein is extracted under reducing conditions in $1 \mathrm{mM}$ $\mathrm{NaHCO}_{3}-1 \mathrm{mV} \beta$-mercaptoethanol. The solution is freed from polymers by 1 hour centrifugation at $100000 \times g$. The protein obtained by this way seems to polymerize irreversibly during precipitation at $70 \%$ ammonium sulphate saturation. A further step between extraction and ammonium sulphate treatment has to be worked out before successful application of this route (fig. $3 \mathrm{a}, \mathrm{b}$ ).

The antigen solutions obtained by routes I, II, and III were further treated by ammonium sulphate fractionation. Samples from route III were observed to precipitate partly at $15 \%$ ammonium sulphate saturation. This precipitate dissolves when insed with $40 \%$ saturated ammonium sulphate solution. This behaviour was not seen with samples from routes $I$ and $I I$. In these, A-antigens were precipitated at $60 \%$ and $75 \%$ saturation as shown in Fig. 3 d.

The immunological tests demonstrate that ammonium sulphate treatment leads more to a concentration than to a significant purification of the A-antigens. Separation of the single components is better obtained by ion exchange chromatography.

A-antigens are not absorbed to CM-cellulose $(20 \mathrm{mM}$ ammonium acetate buffer $\mathrm{pH}$ 5.0) and are completely recovered in the first peak obtained by rinsing the column with the starting buffer. To chromatograph the protein at alkaline $\mathrm{pH}$ different solvents were tested. The most adequate buffer was found to be $10 \mathrm{mM}$ sodium pyrophosphate adjusted to $\mathrm{pH} 8.0$ with citric acid. Antigen preparations obtained from routes, I, II, and III were concentrated to $5-10 \mathrm{mg}$ protein $/ \mathrm{ml}$ and dialysed overnight against this buffer. Under these conditions polymerization is almost completely prevented. The sample is loaded onto a column of DEAE-cellulose $(1.5 \times 10 \mathrm{~cm})$ and rinsed thoroughly with the starting buffer. Then a linear gradient up to $1 \mathrm{M} \mathrm{KCl}$ or to $1 \mathrm{M} \mathrm{KJ}$ is applied. The first elution separates two minor peaks not yet investigated in detail. The main component of the A-antigen group is eluted as a symmetrical peak at $0.3 \mathrm{M} \mathrm{KCl}$ (fig. 4a). This peak can be rechromatographed after adequate reconcentration. In rechromatography a further separation of minor components in the first eluate could be observed. The immunological analysis of fractions of the eluate is given in fig. $4 \mathrm{c}$. A significant increase in homogeneity was effected by chromatography. The rechromatographed fraction 7 shows a single bow in the Osserman immunoelectrophoretic identity test (Fig. 4e).

A very simple and promising way to separate readily bulk yolk proteins from the components of the A-antigen group was tested using immunoabsorption chromatography. Cyanbromide-activated Sepharose 4B was coupled with an IgG-fraction from pooled antisera directed against cricket adult muscle actomyosin. In 2 experiments, 2.7 and $3.1 \mathrm{mg} I g G$ were found to be coupled to $1 \mathrm{~g}$ of the carrier. Loading the columns with $200 \mathrm{mg}$ of total egg protein dissolved in $0.5 \mathrm{M}$ KCl-50mM borate buffer $\mathrm{pH} 8.5$ we recovered $97-98 \%$ of the total protein after 30 $\min$ of equilibration in the first eluate. On raising the molarity of the eluent to $1 \mathrm{M}$ KCl we obtained a first peak of absorbed material. Most of the absorbed material was recovered by lowering $\mathrm{pH}$ to 2.8-2.4 with $1 \mathrm{M}$ glycine-HCl buffer. Rinsing the column with the starting buffer a third peak of absorbed material was obtained. Apparently the absorbed antigen is precipitated in the column after disruption of the antigen/antibody complex but dissolves when the $\mathrm{pH}$ is raised during reequilibration of the absorbent (fig. $4 \mathrm{~b}$ ). One column may be used at least five times 
Table 3. Protein recoveries from purification procedures I-V (cf. Table 2; Figs. 2, 3, 4) Starting material: $200 \mathrm{mg}$ protein/g fresh weight

\section{$\wedge$ 78-82 ug protein/Acheta egg \\ $\triangleq 120 \mu \mathrm{g}$ protein/Gryllus egg}

Rabbit skeletal myosin added: $20-25 \mathrm{mg} / \mathrm{g}$ fresh weight
Purification procedure:
I II
III
IV
$\mathrm{V}$
Protein to be processed further (mg/g fresh weight):

After treatment with:

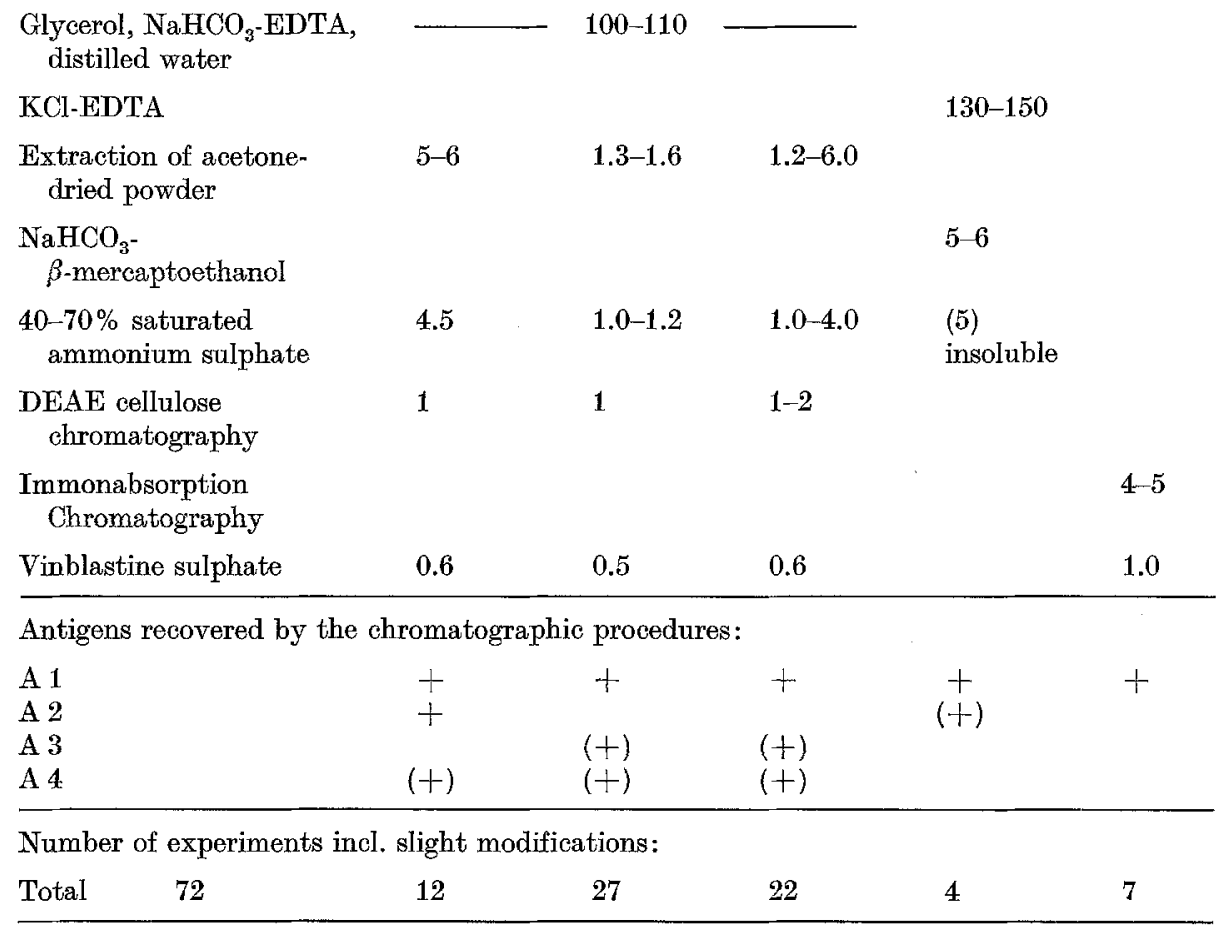

without significant loss in absorption capacity. The pretreatment of the crude antigen solution involves divalent cation removal to prevent polymerization and to loosen the myosin/A-antigen complex. The advantage of the method itself involving solutes of reasonably high ionic strength is the good solubility of almost all plasmodial proteins during chromatography. A further treatment of the A-antigens obtained by this route is under investigation (Fig. 4d).

A survey on the protein recoveries obtained during subsequent purification steps from 72 independent experiments is given in Table 3. Yolk protein extraction by either glycerol or KCl-EDTA removed 70-120 $\mathrm{mg}$ of protein. The most effective step seems to be denaturation of the remainder by the acetone treatment leaving a further $95-145 \mathrm{mg}$ protein in insoluble form. Comparing extractions of the acetone-dried powders and $\mathrm{NaHCO}_{3}-\beta$-mercaptoethanol treatment (route IV) with recoveries obtained by immunoabsorption chromatography, both attempts lead to reasonable results. Due to the specificity of the globulins involved, immuno- 
absorption chromatography gives the most reproducible and reliable protein values. Protein loss during vinblastine sulphate precipitation may occur by a too low concentration of the alkaloid in standard samples not yet investigated in detail.

All procedures lead to an effective purification of the A1 antigen. Route I results in a comparably high recovery of the antigen A2. Final products from the routes I-IV are contaminated with no more than $3-5 \%$ of the antigens A3 and $A 4$ as judged from immunological tests with reconcentrated materials obtained by ammonium sulphate precipitation and/or chromatography on DEAEcellulose.

\section{Molecular Weight of the Monomer and Electron Microscopic}

Observations on Polymers.

First attempts to determine the molecular weight of the purified monomer by analytical ultracentrifugation (Fig. $4 \mathrm{~g}$ ) failed to yield realistic values. To prevent polymerization the experiments were done in $2 \mathrm{mM}$ pyrophosphate $/ 0.5 \mathrm{mM}$ ATP/ $1 \mathrm{mM} \beta$-mercaptoethanol buffers. The only solution preventing significantly polymerization at higher ionic strength (0.3 M KJ-5 mM ATP) was inadequate for analysis by Schlieren optics because of its strong UV-absorption. Using a synthetic boundary cell, the spreading behaviour of the monomeric single peak showed an abnormally low diffusion coefficient tentatively ascribed to electrostatic interactions at low ionic strength. Furthermore, during acceleration some quickly sedimenting material (possibly polymers) was observed interfering with an exact determination of protein concentration. So the determination of the concentration dependence of sedimentation coefficients is prevented due to inherent systematic errors. Tentatively, the same arguments point to considerable intermolecular interactions which interfere with exact determinations by this method.

Alternatively, SDS-disc electrophoresis was used to determine the molecular weight of the monomeric unit. 10 experiments with preparations from different purification procedures gave a molecular weight of $60000 \pm 10 \%$ for the low molecular weight band. On starting from polymers or from ammonium sulphate fractions, considerable amounts of high molecular weight components were observed. Taking into account the immunological homogeneity as demonstrated in Fig. $4 \mathrm{e}$, these components should be polymers up to $n=6-7$ of the monomeric subunit. Higher polymers are not resolved by our $7.5 \%$ acrylamide gels but remain at the top of the gel (Fig. $4 \mathrm{~h}$ ). The 60000 Dalton component seems to accumulate during ultrasonic treatment of SDS-saccharose suspensions of higher polymers.

Polymerization was optimally achieved by dialysis against $0.1 \mathrm{M} \mathrm{KCl}-0.5 \mathrm{mM}$ $\mathrm{ATP} \cdot \mathrm{Mg} \cdot$ and by treatment with vinblastine at $40^{\circ} \mathrm{C}$ in $10 \mathrm{mM}$ pyrophosphate buffer $\mathrm{pH} 7.8 / 1 \mathrm{mM} \beta$-mercaptoethanol (Fig. 4i, k). An example of the latter type of polymer was given previously (Bode and Moser, 1971). Polymers obtained from redialyzed eluate of an immunoabsorption chromatography are shown in Fig. $4 \mathrm{f}$. All polymers obtained from the different fractionation procedures as described above show a similar pearl-chain structure. The beads in the chain are $125 \AA$ in diameter. The chains contain $2-12$ beads. More rarely longer chains were observed up to 40 beads. A structural analysis of these chains will be given in a later paper (Moser et al., submitted for publication). The influence of ATP and divalent cations 
on polymerization of this protein is under investigation. Some preliminary results were given in a previous paper (Moser et al., 1970).

\section{Discussion}

A protein resembling muscular actin and actin-like proteins in some of its properties was purified from the cricket egg plasmodium. Arguments supporting this classification are its solubility in solutes known to depolymerize F-actin to G-actin, and a rather similar behaviour during fractionation procedures. Furthermore, the binding capacity of this protein to rabbit myosin and the observed heavy flocculent precipitation of the myosin/protein complex may provide the classical argument in favour of its characterization as an actin-like protein. The apparent similarity to a protein antigen found in skeletal muscle of the cricket was demonstrated by immunological methods. This antigenic relation can be used to purify the whole actomyosin cross-reacting "A-antigen" group of the early egg plasmodium by immunoabsorption chromatography using heterologous immobilized IgG directed against muscular actomyosin.

The direct proof of the proposed classification has to await further characterization of the protein by amino acid analysis and peptide mapping methods in comparison with cricket muscular actin. From electron microscopic studies of the polymer in the presence of heavy meromyosin (Moser et al., 1970) we are of the opinion that the polymer is able to complex to rabbit myosin in the manner of an actomyosin complex. The aggregates obtained, however, gave very confusing pictures and require further investigation.

Objections against the characterization of the main A-antigen component as an actin-like protein may arise from the structural abnormalities as observed under the electron microscope. In fact, the pearl-chain structure of the polymer seems to be very unusual for an actin polymer. As deduced from structures observed in reversibly depolymerizing insect F-actin preparations, the pearl-chain structure seems to be a very common entity of insect actin filaments lacking some stabilizing factor. These observations are presented in later communications (Moser et al., submitted for publication). Those structures were equally found in late embryonic actin preparations (Bode and Moser, 1971). However, some structures of ribosomal, mitochondrial, and insect blood protein origin resembling the pearlchain structures observed here have to be discussed in this context.

At first glance, our preparation could be taken to be structurally similar to polysomes. This possibility, however, is excluded by the dimensions of the bead particles: they are of much smaller diameter than ribosomal particles. Furthermore, preliminary determinations of ribose and desoxyribose content showed pentose equivalents of no more than total $0.6 \%$ nucleotides resembling the figures obtained for actin from skeletal muscle. These analyses will be extended in connection with our studies on polymerization. Surveying the methods employed in purification of this protein it is very improbable that ribosomes would survive the rigorous treatments used here.

The same may be true for mitochondrial proteins. Glycerol treatment destroys the inner mitochondrial membranes. The particles isolated from these may resemble the polymers of the protein purified here. Very similar structures were 
reported by Kopascyk et al. (1968) for rutamycine-sensitive mitochondrial ATPase. The chain-like particles of the enzyme show a diameter of 80-85 $\AA$ with beaded subunits being of smaller diameter than the particles reported here. Furthermore, our preparations show no ATPase activity. This has to be confirmed by more extended experiments under different adequate conditions. A more consistent argument is the failure of any immunological reactivity of our anti-actomyosin antisera with sonicated mitochondrial preparations. The same antisera react in a pronounced way with the protein purified here.

The insect blood protein "calliphorin" as purified by Munn et al. (1969) may be equally excluded because of its failure to be incorporated in insect eggs. This was confirmed by these authors with immunoelectrophoretic methods. The particles observed by them have a diameter of about $200 \AA$. However, we cannot exclude the possibility that similar proteins may be complexed with myosin in an unspecific manner.

From electron microscopic observations mentioned above the purified protein probably originates from the microfilamentous network observed in periplasmic regions of the glycerol-treated egg. This has to be confirmed by immunofluorescence assays. The difficulties in applying those methods to insect eggs are well known. An unspecific absorption of antisera to yolk components has to be strictly avoided. Those technical difficulties have as yet prevented us from obtaining consistent results.

On the other hand, the functional necessity of a contractile system in the periplasm of developing insect eggs seems to be not improbable. The speed of the organizing movements involved in germ band formation is of the order of slow amoeboidal movements. The strictly programmed spatial course of these movements (Krause and Sander, 1962; Vollmar, 1972) points to a structurally preformed system of contractile elements the order of which has yet to be investigated. Further approach to purify the components involved in this system may lead to a better elucidation of this spatial programming mechanism.

Acknowledgements. This study was supported by the Deutsche Forschungsgemeinschaft (Mo 115/5-6 and Sonderforschungsbereich 46 Molgrudent) and by the Wissenschaftliche Gesellschaft Freiburg. The author is greatly indebted to Prof. Dr. K. Sander and Dr. H. J. Bode for critical and encouraging discussions. The excellent technical assistance of Mrs. S. Collatz and Miss A. Herzfeld throughout this study is gratefully acknowledged.

\section{References}

Adelman, M.R., Taylor, E.W.: Further purification and characterization of slime mold myosin and slime mold actin. Biochemistry 8, 4976-4988 (1969)

Bárány, M., Bárány, K., Guba, F.: Preparation of actin without extraction of myosin. Nature (Lond.) 179, 818-819 (1957)

Bettex-Galland, M., Luscher, E.F.: Extraction of an actomyosin-like protein from human thrombocytes. Nature (Lond.) 184, 276-277 (1959)

Bode, H.J., Moser, J. G.: Zeitfolge der Synthese und funktionellen Integration der Muskelproteine im Grillenskelettmuskel. Verh. dtsch. zool. Ges. 65, 304-309 (1971)

Dejmal, R.K., Brookes, V.J.: Solubility and electrophoretic properties of ovarial protein of the cockroach, Leucophaea maderae. J. Insect Physiol. 14, 371-381 (1968)

Francis, D.W., Allen, R.D.: Induced birefringence as evidence of endoplasmic viscoelasticity in Chaos carotinensis. J. Mechanochem. Cell Motility 1, 1-6 (1971) 
Ishikawa, H., Bischoff, R., Holtzer, H.: Formation of arrowhead complexes with heavy meromyosin in a variety of cell types. J. Cell Biol. 43, 312-328 (1969)

Hartshorne, D. J., Mueller, H.: The preparation of tropomyosin and troponin from natural actomyosin. Biochim. biophys. Acta (Amst.) 175, 301-319 (1969)

Hatano, S.: Conformational changes of Plasmodium actin polymers in the presence of $\mathrm{Mg}^{++}$. J. Mechanochem. Cell Motility 1, 75-80 (1972)

Hatano, S., Oosawa, F.: Isolation and characterization of Plasmodium actin. Biochim. biophys. Acta (Amst.) 127, 488-498 (1968)

Hatano, S., Takahashi, K.: Structure of myosin A from the myxomycete Plasmodium and its aggregation at low salt concentration. J. Mechanochem. Cell Motility 1, 7-14 (1971)

Hatano, S., Tazawa, M.: Isolation, purification, and characterization of myosin B from myxomycete Plasmodium. Biochim. biophys. Acta (Amst.) 154, 507-519 (1968)

Hatano, S., Totsuka, T.: The polymerization of Plasmodium actin in the presence of divalent cations. J. Mechanochem. Cell Motility 1, 67-74 (1972)

Hitchcock, S.: Detection of actin filaments in homogenates of developing muscle using heavy meromyosin. Develop. Biol, 25, 492-501 (1971)

Hunn, I.: Staatsexamensarbeit. Freiburg 1968

Huxley, H.E.: Electron microscope studies on the structure of natural and synthetic protein filaments from striated muscle. J. molec. Biol. 7, 281-308 (1963)

Ikemoto, N., Kitagawa, S., Nakamura, A., Gergely, J.: Electron microscopic investigations of actomyosin as a function of ionic strength. J. Cell Biol. 39, 620-629 (1968)

Körner, H.K.: Die embryonale Entwicklung der symbiontenführenden Organe von Euscelis plebejus Fall. (Homoptera-Cicadina). Oecologia (Berl.) 2, 319-346 (1969)

Kopascyk, K., Asai, J., Allmann, D.W., Oda, T., Green, D.: Resolution of the repeating unit of the inner mitochondrial membrane. Arch. Biochem. Biophys. 128, 602-621 (1968)

Krause, G., Sander, K.: Ooplasmic reaction systems in insect embryogenesis. Advane. Morphogenes. 2, 259-303 (1962)

Lowry, O.H., Rosebrough, N.J., Farr,A.L., Randall, R.J.: Protein measurement with the Folin phenol reagent. J. biol. Chem. 198, 265-275 (1951)

Miki-Noumura,T., Oosawa, F.: An actin-like protein of the sea urchin eggs. Exp. Cell Res. 56, 224-232 (1969)

Morrison, S.L., Koshland, M.E.: Characterization of the J-chain from polymeric immunoglobulin. Proc. nat. Acad. Sci. (Wash.) 69, 124-128 (1972)

Moser, J.G., Bode, H. J., Ade, H., Herzfeld, A.: Progressive muscular dystrophy of insect dorsolongitudinal muscle. Virchows Arch. Abt. B 11, 234-250 (1972)

Moser, J. G., Bode, H.J., Collatz, S., Feldhege, A., Herzfeld, A.: Differenzierung des Aktomyosinsystems während der Morphogenese der Hausgrille, Acheta domesticus L. Verh. dtsch. zool. Ges. 64, 56-60 (1970)

Munn, E.A., Price, G.M., Greville, G.D.: The synthesis in vitro of the protein calliphorin by the fat body from the larva of the blowfly, Calliphora erythrocephala. J. Insect Physiol. 15, 1601-1605 (1969)

Nachmias, V.T., Huxley, H.E.: Electron microscope observations on actomyosin and actin preparations from Physarum polycephalum, and on their interaction with heavy meromyosin subfragment I from muscle myosin. J. molec. Biol. 50, 83-90 (1970)

Nünemann, H., Moser, J.G.: Isolierung und immunelektrophoretische Charakterisierung von Proteinen aus Teilen einzelner Eier der Hausgrille, Acheta domesticus. Verh. dtsch. zool. Ges. - Zool. Anz., Suppl. 33, 113-120 (1969)

Pollard, T.D. (1971), as cited by Francis and Allen (1971) l.c.

Pollard, T.D., Shelton, E., Weihing, R.R., Korn, E.D.: Ultrastructural characterization of F-actin isolated from Acanthamoeba castellanii and identification of cytoplasmic filaments as F-actin by reaction with rabbit heavy meromyosin. J. molec. Biol. 50, 91-97 (1970)

Shapiro, A.L., Vinuela, E., Maizel, J.V.: Molecular weight estimation of polypeptide chains by electrophoresis in SDS-polyacrylamide gels. Biochem. biophys. Res. Commun. 28, $815-820$ (1967)

Shepro, D., Chao, F. C., Belamarich, F.A.: Retardation of clot retraction after incubation of platelets with colchicine and heavy water. Nature (Lond.) 221, 563-565 (1969)

Straub, F. B.: Actin I. Studies Hung. Acad. Sci. 2, 3-15 (1942) 
Szent-Györgyi, A. G.: A new method for the preparation of actin. J. biol. Chem. 192, 361-369 (1951)

Tanaka, H., Hatano, S.: Extraction of native tropomyosin-like substances from myxomycete plasmodium and the cross reaction between plasmodium $\mathrm{F}$-actin and muscle native tropomyosin. Biochim. biophys. Acta (Amst.) 257, 445-451 (1972)

Ts'o, P. O.P., Bonner, J., Eggman, L., Vinograd, J.: Observations on an ATP-sensitive protein system from the plasmodia of a myxomycete. J. gen. Physiol. 39, 325-347 (1956)

Vollmar, H.: Die Einrollbewegung (Anatrepsis) des Keimstreifs im Ei von Acheta domesticus (Orthopteroidea, Gryllidae). Wilhelm Roux' Archiv 170, 135-151 (1972)

Weber, A.: The ultracentrifugal separation of $\mathbf{L}$-myosin and actin in an actomyosin sol under the influence of ATP. Biochim. biophys. Acta (Amst.) 19, 345-351 (1956)

Weihing, R.R., Korn, E.D.: Ameba actin: the presence of 3-methyl-histidine. Biochem. biophys. Res. Commun. 35, 906-912 (1969)

Wessels, N.K., Spooner, B. S., Ash, J.F., Bradley, M. O., Luduena, M. A., Taylor, E.L., Wrenn, J.T., Yamada, K.M. : Microfilaments in cellular and derelopmental processes. Science 171, 135-143 (1971)

Wolf, R.: Kinematik und Feinstruktur plasmatischer Faktorenbereiche des Eies von Wachtelliella persicariae L. (Diptera). Wilhelm Roux' Archiv 162, 121-160 (1969)

Dr. J. G. Moser

Lehrstuhl für Klinische Physiologie

Physiologisches Institut

4000 Düsseldorf

Universitätsstraße 1

Bundesrepublik Deutschland 